\title{
Ethics
}

\section{A Crisis in Chronic Pain Care: An Ethical Analysis \\ Part Two: Proposed Structure and Function of an Ethics of Pain Medicine}

James Giordano, PhD'1, and Michael E. Schatman, $\mathrm{PhD}^{2}$

From: ${ }^{1}$ Georgetown University, Washington, DC; Center fo Neurotechnology Studies,

Potomac Institute of Policy

Studies, Arlington VA; and ${ }^{2}$ College of Osteopathic Medicine, Yakima, WA.

Dr. Giordano is SamueliRockefeller Professor,

Departments of Medicine and Neurosciences, Scholar-inResidence, Center for Clinical Bioethics, Georgetown University Medical Center, Washington, DC; and Senior Fellow and Director,

Center for Neurotechnology

Studies, Potomac Institute of

Policy Studies, Arlington, VA.

Dr. Schatman is Assistant

Professor, Department of Family

Medicine, Pacific Northwest

University of Health Sciences,

College of Osteopathic Medicine, Yakima, WA

Address correspondence: Dr. James Giordano Departments of Medicine and Neurosciences

Georgetown University Medical Cente

4000 Reservoir Rd,

Bldg D, Rm 238

Washington, DC 20057

E-mail: jg353@georgetown.edu

Disclaimer: Funded by a grant from the L.S. Rockefeller Trust, and an American Academy of Pain Medicine-Pfizer National Visiting Professor Award (JG)

Conflict of interest: None.

Free full manuscript www.painphysicianjournal.com
In this paper, we propose a constructive approach to an ethics of pain medicine that is animated by a core philosophy of medicine as specific and focal to the uniqueness of pain, the pain patient, and the pain clinician. This philosophy of pain medicine 1) defines the nature of pain, 2) recognizes the variability and subjectivity of its expression in the pain patient, 3) acknowledges and explicates the vulnerabilities rendered by pain, 4) describes the inherent characteristics and asymmetries of the patient-clinician relationship, and 5) defines the ends of pain care. That these ends entail the provision of "good" care links the epistemic domains of pain medicine to its anthropologic focus and ethically sound conduct.

We posit that an ethics of pain medicine should define the profession and sustain the practice. Facts establish (the need for) certain duties and rules of pain medicine. These emphasize the duty to self and others, and an appreciation for relational asymmetries, and dictates that those who enter the profession of pain medicine should be generally aligned with this set of core practical and ethical affirmations and duties.

To maintain contemporary relevance, rules, duties, and moral reasoning must adjust to changing conditions. Applied ethics shape the practice within the infrastructure of core rules and duties of the profession. An applied ethics of pain medicine must be pragmatic, and therefore, cannot rely upon, or be reduced to, a single principle or ethical system. A number of ethical systems (such as the use of principles, utilitarianism, casuistry, feminist/ care orientations) all have relative merit and potential limitations. We argue that the obligation to recognize ethical issues, and utilize knowledge to best reflect appropriate moral values rests upon the clinician as a moral agent, and therefore advocate the relevance and importance of an agent-based virtue ethics, recognizing that virtue ethics cannot stand alone, but must be employed within a larger system of ethical intuition. Yet, if such a structure of normative and applied ethics is to be realized, moral consideration must guide evaluation of the current system of pain care, and provide direction for the development and implementation of therapeutically and ethically integrative pain medicine for the future.

Key words: Pain medicine, normative ethics, applied ethics, deontology, virtue ethics, humanities

Pain Physician 2008; 11:5:589-595 
D escribing the nature of problems inherent to chronic pain care most certainly represents an important step toward defining what limitations and ethical issues confront the profession of pain medicine (1). The interaction of circumstances, agents, moral subjects, and (social, economic, and legal) forces in the medical environment generate these problems, and such forces must also be considered when proposing potential resolutions. If an ethics of chronic pain care is to be viable, it must be based upon fact(s), but it must be equally committed to core values of medicine that establish the moral premises upon which pain care is built (2). In this way, the philosophical constructs of pain care become consistent with, and sustained by, the goals and ends of medicine as both an individual and public good (3).

To be sure, there are aspects of pain medicine that require specificity of the principal philosophic domains and tasks (i.e. epistemology, anthropology, and ethics). In this paper, we propose a constructive approach to an ethics of pain medicine that is animated by a core philosophy of medicine as specific and focal to the uniqueness of pain, the pain patient, and the pain clinician.

\section{Importance of a Philosophy of Pain Medicine}

A philosophy of pain medicine 1) defines the nature of pain, 2) recognizes the variability and subjectivity of its expression in the pain patient, 3) acknowledges and explicates the vulnerabilities rendered by pain, 4) describes the inherent characteristics and asymmetries of the patient-clinician relationship, and 5) defines the ends of pain care, both specifically, and as relevant to medicine, writ large $(1,3,4)$. That these ends entail the provision of "good" care links the epistemic domains of pain medicine to its anthropologic focus and ethically sound conduct.

The anthropologic basis of pain medicine is realized through the provision of care - as a humanitarian act - within the clinical encounter that occurs between clinican and patient, existing de communitas (in community) $(5,6)$. At the most proximate level, this involves sharing common moral values of the healing interaction, namely that the patient seeks the clinician based upon the clinician's professed knowledge, skills, and ability (7). More broadly, this act of profession provides an open invitation to any and all pain patients, and in this way, can be seen as both covenantal and offering a social/public good $(8,9)$. While it cannot be denied that some elements of the clinical relationship may be supported by social contract (10), complete contractual influence is not possible given the nondiscretionary nature of pain, and relative inequalities (of knowledge, skill, and ultimately, decisional power) that exist between clinician and patient. The primacy of the patient's best interest is non-negotiable and establishes the foundation of the clinical relationship, and ultimately the individual and public trust in (pain) medicine, at large (11). Thus, it becomes evident that such anthropologic dimensions of pain care inform and compel the ethics of pain medicine.

\section{An Ethics of Pain Medicine}

We posit that an ethics of pain medicine should define the profession and sustain the practice. While explication of a putative meta-ethics of pain medicine is beyond the scope of this paper, it is important to note that such a meta-ethics is needed to describe the nature and meaning(s) of moral terms and constructs, and the obligations these entail. This metaethics requires a balanced cognitivist and subjectivist foundation. Cognitivist aspects reflect that particular practical and moral truths inherent to pain medicine as a profession are both valid and viable. However, incorporating these truths into the moral decisions of practice involves subjective valuation, reflection, and responses of individual clinicians as moral agents (12).

In other words, while facts (of pain, therapeutics, nature of clinical practice, etc.) may be objectively known, how this knowledge is to be used in moral decision-making and definitions of "good" (and "bad") are less objective. In light of this, any attempt to construct an ethics of pain medicine must clearly delineate what facts are essential to the objective framework of the profession so as to establish foundational responsibilities and duties that must be upheld in order to ensure its authenticity. These facts are based upon the most current knowledge (of pain, burdens, risks, and benefits of treatment, etc.), and provide practical truths to direct the moral affirmations of pain medicine as a profession, and obligations of individual clinicians in practice.

\section{Primary Structure: Deontic Normative EThics}

As Baggini and Fosl note, "...meta-ethics colors normative ethics" (13). Moreover, we agree with Shelly Kagan (14), that the distinction between normative 
and applied ethics can be somewhat arbitrary and is really more of a continuum of concept and action. The nature of a "profession" dictates 1) the acquisition of specialized training, knowledge and skill(s), and 2) the development and use of specific constructs and rules (i.e. a deontic foundation) that enable self-governance and policing. This acknowledges that facts establish (the need for) certain duties and rules of pain medicine, and those who enter the profession of pain medicine must be committed to its realities, tasks, efforts and duties $(15,16)$. Table 1 lists what we feel are representative duties and rules, based in part upon the work of Richard Ryder (17), Thomas Nagel (18), Richard Zaner (19), and Edmund Pellegrino (20).

The deontic nature of this approach is decidedly Kantian, and emphasizes the duty to self and others, and an appreciation for relational asymmetries (21). In defining the profession, such duties and rules are, in fact, imperative. However, to avoid being procrustean they must also allow for individual embededness in history, traditions, and culture, and acknowledge (a non-relativistic) pluralism (22). To be sure, to maintain any contemporary relevance, rules and duties (and moral reasoning) must adjust to changing conditions (23).

\section{Secondary Structure: Applied Ethics}

Applied ethics that shape the practice work within the infrastructure of core rules and duties of the profession. An applied ethics of pain medicine must be pragmatic, and therefore, cannot rely upon, or be reduced to a single principle (or ethical system). Intentions, actions, and consequences (in the clinical environment) are all ethically relevant (24). Hence, the practical agency of the pain clinician (i.e.- literally her agency as engaged in the provision of "good" [25]) is necessarily therapeutic and moral. Personal and cultural values and beliefs contribute to each clinician's moral compass, and therefore are instrumental in determining what and why various ethical systems have appeal and utility in guiding the moral decisions of clinical practice. So while coarse-grained alignment of clinicians' values and beliefs with the deontic framework of pain medicine is important, the applied ethics of practice involves other ethical systems that are resonant with individual clinicians' moral reasoning on a more fine-grained level. Obviously, a number of ethical systems have relative merit in this regard (a review of ethical systems as relevant to pain management is provided by Chessa [26]).
Table 1. Representative duties and rules of a normative ethics of pain medicine

1. Entering the practice of pain medicine is discretionary and must reflect personal acknowledgement and adherence to a philosophy of pain medicine.

2. A core ethic of pain care reflects the belief that pain is "real."

3. This core ethic is based upon unselfishness: the experiences of the moral patient are always of greater moral importance than the motives of the moral agent.

4. Pain and suffering are profound harms.

5. There is a moral objective and obligation to reduce the pain of patients: This moral standard applies equally to all painient individuals.

6. Whatever benefits, it is wrong to deliberately produce or allow pain that is prolonged or severe.

7. As a general rule, we should adopt the precautionary principle that whenever the potential for pain is uncertain in a living being, it should be assumed.

8. There is a duty upon those caring for pain patients to acknowledge the facts and realities of pain as physiological and psychological event (and recognize co-morbid syndromes and conditions).

9. There is a duty for those caring for pain patients to acknowledge the subjectivity of pain.

10. There is a duty for those who profess to be pain clinicians to accept the difficulties, burdens, and responsibilities of caring for those in pain.

Of these, the use of mid-level principles (beneficence, non-maleficence, respect for autonomy, justice) is undoubtedly one of the most familiar and widely used in medicine (27). Using principles within a rulebased framework allows for some situational interpretation of what principle (or order of principles) best meet core professional responsibilities, while accommodating the interpersonal relationships and issues of a particular case (27). However, one of the problems frequently encountered when using the principlist approach is the limitations of face-value reliability of the principles themselves (28). Often, a given principle, or a particular ordering of principles, can only be employed if specific constraints on situations, relations, and/or consequences are considered (i.e. considerations ceteris paribus - all other things being equal 
[29]). The problem is that such specifications and constraints are rarely possible given the diversity of situations that arise in the practice of pain medicine. This would seem to necessitate a moral particularism and/ or situation ethics, which while allowing more finergrained evaluation, might also be viewed as contradictory to principlism, on the whole $(30,31)$.

To accommodate the specifics of individual cases and still frame ethical decision-making within some grounding framework or set of precedents, the casuistic method is often employed. Casuistry - the process of ethical analysis in which a particular case is compared to prior paradigmatic cases of similar circumstance - is derived from English legal practice, and thus, may have certain value in bridging practical ethics to law (32). In this latter regard, the casuistic method is frequently used when ethics committees engage healthcare administrations and/or legal departments to resolve ethical issues or formulate policy (33). Yet, despite the apparent similarity of certain cases, important details very often differ, and evaluating and weighing these differences is critical and rarely without some implicit or explicit bias.

Casuistic decisions tend to be oriented toward maximizing good outcomes, and therefore, could be (and sometimes are) coupled with utilitarian approaches. John Baron has advocated a form of utilitarianism that examines the capacity of rules and actions to maximize patient-centered care (34). The provision of such care could entail rules and acts that produce the greatest overall good (viz. total utilitarianism), or that afford good level of care averaged across the greatest number of patients (viz. average or welfarist utilitarianism). The value of this approach is that it appeals to moral intuitionism, and may accommodate some level of commutative and distributive justice (35). The attractiveness of these types of utilitarian models is that they place considerable value on human wellbeing as a primary good. Still, the utilitarian approach is consequentialist, while consequences (particularly those that are good) are important, any practical, ethical reasoning must also regard circumstance, agents, intentions, and acts/means. Toward this end, greater methodologic rigor may be required in the analysis, and process of ethical decision-making itself.

Carol Gilligan (36) and Annette Baier (37) have claimed that true moral consideration and decisionmaking require a deeper understanding of relational asymmetries and the marginalizing effects of illness and vulnerability. These concepts form the basis of feminist and care ethics, and such approaches have been increasingly advocated as forms of ethics that reflect the circumstances and contingencies of "healing-oriented" healthcare fields (38), including chronic pain management (39). Yet, as Julia Pedroni notes, while feminist and care ethics may offer sensitive, "other-centered" methodologies and practices, their utility may require definition of therapeutic boundaries and the type(s) and levels of good that are appropriate in the clinical relationship (39) intellectual and moral activities that Baier states comport with, and require virtue (37).

Table 2. Ethical approaches addressed in text: Basic focus, scope and limitations

\begin{tabular}{|l||}
\hline Some Representative Ethical Systems \\
\hline - Priniciplism: Focus upon mid-level, prima facie principles of beneficence, non-maleficence, respect for autonomy, justice \\
\hline - Utilitarianism: Seeks to provide overall or average "good"; "welfarist" orientation \\
\hline - Feminist/Care Ethics: Consideration of inequalities of position and relationship, marginalization, focus upon care \\
\hline - Casuistry: Analysis of paradigmatic prior cases as relevant \\
\hline - Communitarianism: Intentions and actions to support common values, ideals of good \\
\hline Potential Limitations of These Ethical Approaches \\
\hline - Principlist Approach: Collision/conflict between principles; how might principles be "ordered"? \\
\hline - Utilitarian Approach: Decision of what constitutes the "best fit" good, or maximal achievement of good \\
\hline - Feminist Approach: Problematic issues with therapeutic boundaries and limits within nature/scope of care \\
\hline - Casuist Approach: "Which cases, what factors?", potential for selection and judgment bias \\
\hline - Communitarian Approach: Decision and negotiation of common value(s), ideals, and rules may subordinate individual(s) to group(s) \\
\hline \hline
\end{tabular}




\section{The Clinician as Moral Agent}

Every ethical system has potential merit and limitations (see Table 2), and thorough analysis of circumstance, action, and consequences - taken together with critical self-reflection upon one's individual moral compass - are vital to determine which ethical approach (or combination of approaches) may be most useful and meaningful. The obligation to apprehend circumstance, recognize ethical issues, and utilize knowledge to best reflect appropriate moral value(s), in the end, rests upon the clinician as a moral agent who is insightful and responsive to the relative needs of pain patients and to the inter-dependence of knowledge, intentions, acts, and consequences. Even if an analytic or statistical approach is used to resolve clinical equipoise and ethical questions, it is incumbent upon the clinician to utilize the right intellectual capacities, the right knowledge, and moral values when implementing medical decisions to effect the provision of good care (4).

It is for these reasons that we advocate the relevance and importance of an agent-based ethics. Such agency obligates technical and intellectual competence, as well as self-understanding (of emotions, values, capabilities, and limits). It has been claimed that there is a strong, if not direct, relationship between agentic integrity and good action, such that 1 ) intellectual skill and emotional maturity are necessary to comprehend and enact standards of morality (40), and 2) different types of knowledge inform and uphold particular traits of character so as to accept moral responsibility and resist moral lassitude (41). These ingrained dynamics of character - i.e. virtues - establish the ability for intellectual and moral discernment and practical sensibility, and we believe that certain intellectual and moral virtues (e.g. prudence, reverence, benevolence, compassion, veracity, fortitude) are not only vital traits of the pain clinician, but are equally important ethical cornerstones for the sound practice of pain care $(2,3,15)$. Table 3 provides a summary of agent-based virtue ethics, its relative advantages, and purported limitations.

As with any other ethical system, virtue ethics is not without limitation(s) or criticism(s), and we recognize that the virtues cannot (nor perhaps should not) be considered in isolation (Table 3) $(15,42-44)$. But we reject the contention that a virtue ethics of pain medicine is not possible given the environment of contemporary society. Our premises in support of agent-based virtue ethics are relatively straightfor-
Table 3. Agent-based, virtue ethics: Foundations, advantages, and limitations

An Ethics of Virtue

- Focuses upon moral character of the agent

- Emphasizes reliance upon intellectual and moral traits of character (virtues) that predispose the agent toward "good" (“...ways of knowing, ways of reason, ways of acting")

- Intellectual virtues theoretical knowledge, experiential knowledge, contextual knowledge, practical wisdom

- Moral virtues reverence, benevolence, veracity, fidelity, intellectual honesty, courage, relative effacement of selfinterest, practical wisdom

Advantages

- Recaptures ancient tradition of ethics

- Encourages and cultivates excellences of human character

- Focus upon rationality

- Reflects and comports Hippocratic and Oslerian ideals of "core traits" of the clinician

- Enables more modernist emphasis upon empirically-based articulation of knowledge and skill(s)

- Compatible with other ethical systems (see text)

Limitations

- Non-consensus of virtues or values

- Requires notion of "common good" or "common moral framework"

- Potential conflict of virtue(s) with particular institutional system(s) of ethics, policy and/or law

- Problem of teaching and assessing virtue

- Questions of "frank necessity" of virtue(s) in principle- or rule-based systems

Refer to references $3,4,15$ and 42 for a disputation of advantages and limitations.

ward: pain is complex, the treatment of pain patients can be demanding, and the right and good articulation of pain medicine in the current economic, legal and social environment can be difficult. The person entering the field cannot underestimate these factors, take them for granted, nor trivialize the importance of the responsibilities that these variables foster. Simply, we argue that certain intellectual and moral virtues are required of the pain clinician, to both enable the knowledge and skill required for therapeutic capacity, and to embrace core values and appropriately utilize other ethical approaches to execute moral agency. A more complete discussion of a virtue-based ethics of pain medicine, and of particular virtues that are important to the therapeutic and moral agency of the pain clinician is addressed in previous work $(2-4,15,42-44)$. 


\section{Ethical Agency in Practice: Toward an Integrative framework of Pain Medicine}

While we propose a deontic structure of the profession of pain medicine, and what normative and applied ethical systems best enable its practice, we must also consider the ethically complex milieu of pain care within the environment of contemporary medicine and society, at large. Numerous disciplines (e.g. anesthesiology, neurology, physical medicine, psychiatry/ psychology, etc.) provide pain care through somewhat differing theoretical and technical approaches. Yet, we feel that all must be 1) based upon a contemporary neurophilosophy of pain $(45,46)$, and 2 ) consistent with and adherent to the core philosophical premises and ends that define medicine. Ethical systems analyze and determine how and why clinically relevant, moral decisions can be made, and it is evident that within a basic deontic structure of pain medicine, a number of ethical systems are possible and valid. Yet, if such a structure of normative and applied ethics is to be realized, moral consideration must guide evaluation of the current system of pain care and provide direction for the development and implementation of therapeutically and ethically integrative pain medicine for the future.

\section{Acknowledgements}

This work was supported by a grant from the Laurance S. Rockefeller Trust, and an American Academy of Pain Medicine, Pfizer National Visiting Professorship at Texas Tech University Health Sciences Center, Lubbock, TX (JG). The authors thank Holly Long for administrative and editorial assistance and Sherry Loveless for editorial assistance and graphic artistry.

\section{References}

1. Giordano J, Schatman, M. A crisis in pain care- An ethical analysis. Part one: Facts, issues, and problems. Pain Physician 2008; 11:483-490.

2. Giordano J. Ethics of, and in pain medicine: Constructs, content, and contexts of application. Pain Physician 2008; 11:1-5.

3. Giordano J. Moral agency in pain medicine: philosophy, practice and virtue. Pain Physician 2006; 9:41-46.

4. Giordano J. Pain, the patient and the physician: Philosophy and virtue ethics in pain medicine. In: M Schatman (ed.) Ethical Issues in Chronic Pain Management. Taylor and Francis, NY, 2007.

5. Giordano J. The moral community of the clinical pain medicine encounter. Prac Pain Management 2006; 6:60-63.

6. Wynia MK, Latham SR, Kao AC, Berg JW, Emanuel LL. Medical professionalism in society. NEJM 1999; 341:1612-1616.

7. Pellegrino ED. The medical profession as moral community. Bull NY Acad Med.1990; 66:221-232.

8. May WF. Contending images of the healer in an era of turnstile medicine. In: JK Walter, EP Klein (eds.) The Story of Bioethics: From Seminal works to Contemporary Explorations. Georgetown University Press, Washington, DC, 2003, 149-162.
9. May WF. Code, covenant, contract or philanthropy? The Hastings Center Report 1975; 5:29-38.

10. Veatch RM. The impossibility of a morality internal to medicine. J Med and Philosophy 2001; 26:621-642.

11. Pellegrino ED, Thomasma DC. For the Patient's Good: The Restoration of Beneficence in Health Care. Oxford University Press, NY, 1987.

12. Giordano J. A meta-ethics of pain medicine: Structure for the profession, function of the practice. In: Giordano J (ed). Maldynia: Multi-Disciplinary Perspectivces on the Illness of Chronic Pain. Informa, NY, In press.

13. Baggini J, Fosl PS. The Ethics Toolkit: $A$ Compendium of Ethical Concepts and Methods. Blackwell, Oxford, UK, 2007, 149.

14. Kagan S. Normative Ethics. Westview Press, Boulder, CO, 1998.

15. Maricich Y, Giordano J. Pain, suffering, and the ethics of pain medicine: Is a deontic foundation sufficient? Am / Pain Management 2007; 17:130-138.

16. Giordano J. Pain as disease and illness: Part 2 - Structure and function of the ethics of pain medicine. Prac Pain Management 2006; 6:65-68.

17. Ryder RD. Painism: a Modern Morality. Centaur Press, London, 2001.
18. Nagel T. Mortal Questions. Cambridge University Press, Cambridge, 1979.

19. Zaner R. Physicians and patients in relation: Clinical interpretation and dialogs of trust. In: G. Khushf (ed). Handbook of Bioethics: Taking Stock of the Field from a Philosophical Perspective. Dordrecht, Kluwer, 2004, p.223-250.

20. Pellegrino ED. Toward a reconstruction of medical morality: The primacy of the act of profession and the fact of illness. J Med Phil 1979; 4:32-56.

21. Kant I. Groundwork of the Metaphysics of Morals. M. Gregor (ed). Cambridge University Press, Cambridge, 1998.

22. Berlin I. The idea of pluralism. In: Anderson WT (ed). The Fontana Post-modernism Reader. Fontana Press, London, 1996.

23. Nagel, T. The View from Nowhere. Oxford University Press, NY, 1986

24. La Follette H. Pragmatic Ethics. In: LaFollette H. (ed.) Blackwell Guide to Ethical Theory. Blackwell, 2000, Malden, MA, 400-419.

25. MacIntyre A. After Virtue: A Study in Moral Theory (2nd ed). University of Notre Dame Press, Notre Dame, 1984.

26. Chessa F. Ethics: History and theory. In: Boswell MV, Cole BE (eds). Weiner's Pain Management: A Practical Guide 
for Clinicians. 7th ed. CRC Press, 2005, Boca Raton, 1355-1376.

27. Beauchamp TL, Childress JF. Principles of Biomedical Ethics, 5th ed, Oxford, NY, 2001.

28. Clouser KD, Gert B. A critique of principlism. The Journal of Medicine and Philosophy 1990; 15:219-236.

29. Marquard O. Farewell to Matters of Principle. Oxford University Press, Oxford, 1989.

30. Fletcher J. Situation Ethics. The Westminster Press, Philadelphia, PA, 1966.

31. Hooker B, Little M. Moral Particularism Clarendon Press, Gloucestershire, UK, 2000.

32. Miller RB. Casuistry and Modern Ethics: A Poetics of Practical Reasoning. University of Chicago Press, Chicago, 1996.

33. Lo B. Resolving Ethical Dilemmas: A Guide for Clinicians. Williams and
Wilkins, Baltimore, 1995.

34. Baron J. Against Bioethics. MIT Press, Cambridge, 2006.

35. Moore M. Objectivity in Ethics and Law. Ashgate, Burlington, VT, 2004.

36. Gilligan C. In a Different Voice: Psychological Theory and Women's Development. Harvard University Press, Cambridge, MA, 1993.

37. Baier AC. Moral Prejudices: Essays on Ethics. Harvard University Press, Cambridge, 1996.

38. Sherwin S. No Longer Patient: Feminist Ethics in Healthcare. Temple University Press, Philadelphia, PA, 1992.

39. Pedroni J. What does pain management really want from a feminist/care ethics? In: J Giordano, MV Boswell (eds) Pain Medicine: Philosophy, Ethics, and Poli$c y$. Linton Atlantic Press, Lexington, KY, In press.

40. Mele AR. Autonomous Agents: From Self-Control to Autonomy. Oxford Uni- versity Press, Oxford, 1995.

41. Aristotle. Nicomachean Ethics. Book VI. D. Ross (trans.) Oxford University Press, London, 1966.

42. Giordano J. Agents, intentions and actions: moral virtue in pain medicine. Prac Pain Management 2006; 6:76-80.

43. Niebroj LT, Jadamus-Niebroj D, Giordano J. Toward a moral grounding of pain medicine: Consideration of neuroscience, reverence, beneficence, and autonomy. Pain Physician 2008; 11:7-12.

44. Giordano J. Toward a core philosophy and virtue-based ethics of pain medicine. Pain Practitioner 2005; 15:59-66.

45. Giordano J. A big picture: neurogenesis, pain and the reality and ethics of pain medicine. Prac Pain Management 2007; 7:37-52.

46. Giordano J. Complementarity, brainmind, and pain. Forsch Komplementmed 2008; 15:2-6. 